\title{
Effects of magnesium oxide nanoparticles on memory impairment induced by postpartum depression model
}

\author{
Farzaneh Zadedarvish, Mahnaz Kesmati ${ }^{*}$ iD, Lotfollah Khajepour, Mozhgan Torabi \\ Department of Biology, Faculty of Sciences, Shahid Chamran University of Ahvaz, Ahvaz, Iran
}

\begin{abstract}
Introduction: Plasma magnesium level is reduced after postpartum depression in female and this reduction can cause memory impairment. As regards the magnesium has antidepressant activity and it's deficiency leads to depression, the aim of this study was evaluating the effect of magnesium in form of magnesium oxide nanoparticles (MgO NPs) on memory retrieval in a postpartum depression model.

Methods: Adult female mice $(27 \pm 3 \mathrm{~g})$ were divided into groups of control, depressed and depressed recipient of MgO NPs $(1,2.5,5$ or $10 \mathrm{mg} / \mathrm{kg})$ as an acute and chronic administrations. For induction of postpartum depression, chronic administration (5 days) of progesterone was used and three days after stopping administration, the depressive behavior was evaluated by tail suspension test. Passive avoidance memory and locomotor activity have done 24 hours after training using the step-down and open field devices, respectively.
\end{abstract}

Results: Induction of postpartum depression model by the withdrawal of progesterone significantly decreased the memory retrieval. Acute administration of MgO NP significantly improved depression and memory impairment in a dosedependent manner, while chronic administration showed less improvement in depression and memory. There was no difference between locomotor activities in all groups.

Conclusion: It seems that acute administration of MgO NPs could be more suitable supplement than its chronic ones for improving depression and prevent memory impairment induced by postpartum depression. Probably the duration of nanoparticles administration can be a determining factor in their efficacy.

http://dx.doi.org/10.32598/ppj.24.1.80

\section{Keywords:}

Magnesium oxide;

Memory;

Nanoparticle;

Postpartum depression

\section{* Corresponding author:}

Mahnaz Kesmati

Email:

m.kesmati@scu.ac.ir

Tel: +98 (61) 33331045

Received 18 July 2019;

Received in revised form 9

December 2019; Accepted 15

December 2019

\section{Introduction}

Postpartum depression (PPD) is one of the most common complications problems after childbirth (Almeida et al., 2012) and in case of impact on quality of life for all family members can have serious and even lead to disruption of the relationship between mother and baby during the lifetime of the early development of the infant's brain (Harati et al., 2014). Several factors are involved in causing postpartum depression (Lashkaripour et al., 2012). The most important collections of biological factors, including effects of hormones like drop of estrogen and progesterone levels, neurotransmitters function and malnutrition (Lashkaripour et al., 2012; Nikseresht et al., 2012). 
Secretion of sex hormones increase during pregnancy, but decease significantly after delivery and this reduction can cause the onset of postpartum depression (Osaghae et al., 2019; Harati et al., 2014). Progesterone alone or in combination with estrogen can reduce depression perhaps by interaction with neurotransmitters systems (Walf et al., 2010; Nikseresht et al., 2012). Pregnancy can has negative effect on memory (Cuttler et al., 2011). Memory defects are seen during pregnancy that in which short-term and the working memories can be disrupted (Almeida et al., 2012; Logan et al., 2014).

On the other hand, magnesium as a trace element in the body is involved in the pathology and treatment of depression and can affect neurotransmitter release, metabolism and the nervous system activity (Murck et al., 2002; Wojcik et al., 2006). Studies have shown that magnesium has antidepressant activity and magnesium deficiency leads to depression (Eby and Eby, 2010; Nikseresht et al., 2012). In animals, magnesium reduces immobility in the forced swim test similarly to the imipramine as a conventional antidepressant (Spasov et al., 2008). The foundation of learning (long-term potentiation [LTP]), memory and depression is N-methyl-D-aspartate (NMDA; one of glutamate ionic receptor) receptors (Sarreshtehdar et al., 2012; Hayashi et al., 2014). Magnesiumdepletion is specifically deleterious to neurons by causing NMDA-coupled calcium channels to be biased towards opening because magnesium is nature's NMDA receptor blocker (Hayashi et al., 2014).

Magnesium plays a role in many of the pathways, enzymes, hormones and neurotransmitters involved in mood regulation (Tarleton et al., 2017). In low magnesium states, high levels of calcium and glutamate may deregulate synaptic function, resulting in depression (Deutschenbaur et al., 2016; Tarleton et al., 2017). Depression and magnesium are also both associated with systemic inflammation. Since the mechanism of magnesium's role in depression is still not clear, it is difficult to say why this relationship with antidepressants may exist. The mechanism may be related to their anti-inflammatory properties or role in NMDA and glutamate activity. Magnesium supplementation may allow for lower antidepressant dosage or avoid the need for use of a second medication, both of which could reduce overall side effect burden (Tarleton et al., 2017).
Magnesium increases BDNF expression, which may be connected with the reduction of NMDA receptor function. Inhibition of the glycogen synthase kinase-3 (GSK-3) enzyme is involved in the mechanisms of action of antidepressant drugs. Since magnesium is a potent inhibitor of this enzyme, GSK-3 may well be a possible target of antidepressant activity of this ion (Szewczyk et al., 2008). Some studies have demonstrated that the NMDA receptor antagonists exhibit antidepressant-like activity in animal models (Poleszak et al., 2004; Li et al., 2010). Long-term oral administration of magnesium supplements, enhanced brain magnesium levels and leading to increased synaptic plasticity (Hayashi et al., 2014). Magnesium increases the ability of the animal to store the data in memory caches and the power to recall stored information (Sarreshtehdar et al., 2012).

Magnesium deficiency has been shown to lead to changes in the functioning of the central nervous system, especially in the glutamatergic transmission in the limbic system and cerebral cortex brain regions that play important roles in the etiopathogenesis of depression. However, despite magnesium's wellknown involvement in the voltage gating function of the NMDA receptor, evidence pointing towards direct magnesium-induced changes in NMDA channels in the expression of depression-like behavior is scarce. Evidence supports the possibility that magnesium deficiency disrupts neuronal function by means of increasing neuronal calcium flow, thereby resulting in increased nitric oxide, a toxic reactive oxygen species (ROS) that leads to neuronal swelling and death (Wang et al., 2018). Magnesium could potentially exert antidepressant effects through its role in serotonergic, noradrenergic and dopaminergic neurotransmission (Wang et al., 2018).

In the recent years, nanotechnology and new nanomaterials with a wide range of important applications in the cellular and molecular level, have become more widespread (Suresh and Utkarsh, 2013; Kesmati et al., 2014). Metal oxide nanoparticles are used for various purposes of medical sciences (Adabi et al., 2017; Mohammed et al., 2017). However, limited research in the field of direct application of nanoparticles in the body is taken (Suresh et al., 2013). Today magnesium oxide nanoparticles ( $\mathrm{MgO}$ NPs) are using for medical treatment and drugs transfer (Abdolahzadeh et al., 2014; Mohammed et al., 2017). MgO NPs after entering the body can be 
more effective than bulk form (Wang et al., 2012; Jahangiri et al., 2013). They have a higher surface to volume ratio compared to conventional composition and increased absorption rate and nanoparticles are affected better and faster than their natural forms (Archakov et al., 2010).

Thus postpartum depression impairs learning and memory (Almeida et al., 2012; Kataja et al., 2017) and magnesium levels in mothers are reduced in late pregnancy and postpartum (Grossi et al., 2017), magnesium can reduce postpartum depression (Kronqvist, 2011; Kesmati et al., 2017), and our previous studies have shown that MgO NPs could affect learning and memory (Kesmati et al., 2016). In this study, the effect of acute and chronic treatment of $\mathrm{MgO}$ NPs has been investigated on learning and memory impairment induced by postpartum depression in adult female mice.

\section{Materials and methods}

\section{Animals}

In this experimental research 84 adult female albino NMRI mice $(27 \pm 3 \mathrm{~g})$ were used. Animals were housed in groups of 7 with free access to food and water unless during the test time and under temperature controlled room $\left(24 \pm 1^{\circ} \mathrm{C}\right)$ with a 12 hours light/ dark cycle. All mice were allowed to adapt to their caging environment for at least two weeks prior to the PPD induction. All experiments were carried out in accordance with institutional guidelines for animal care and use of laboratory animals that approved by Shahid Chamran University of Ahvaz, Ahvaz, Iran (Code number: EE/96.24.3.88376/scu.ac.ir).

\section{Experimental design and components PPD induction:}

For induction of PPD, mice received progesterone $(5 \mathrm{mg} / \mathrm{kg})$ for 5 consecutive days that had been prepared in the sesame oil solvent (Nikseresht et al., 2012). After 5 days, progesterone infusion was interrupted for 3 days and on the eight days, behavioral tests were performed. MgO NP (lolitech Co, Germany, particle size $<100 \mathrm{~nm}$ ) was dispersed in $\% 0.9$ saline by the ultrasonic bath for $16 \mathrm{~min}$ and shaken for $1 \mathrm{~min} \backslash$ before of each injection. All components were injected intraperitoneally in volume of $0.05 \mathrm{ml} / \mathrm{kg}$ (Nikseresht et al., 2012). Training and injections and all behavioral experiments took place during the light cycle and were conducted from 8:00 am to $14: 00$ pm. In acute injection, MgO NP was administered $30 \mathrm{~min}$ before the test.

\section{Animals grouping}

To study the effect of MgO NP on memory impairment in depressed female mice, the animals were divided into 12 groups that are presented in Table 1. Tests on animals were performed as follows: on the first day of the experiment, 30min after $\mathrm{MgO}$, saline or sesame oil injections and then tail suspension test was used to measure the

Table 1: Animals grouping and components injection.

\begin{tabular}{|c|c|c|c|c|}
\hline \multirow{2}{*}{\multicolumn{2}{|c|}{ Groups }} & \multicolumn{3}{|c|}{ Days } \\
\hline & & $1-5$ & $6-7$ & 8 \\
\hline 1 & Saline & Saline & - & Saline + tests \\
\hline 2 & Vehicle & Sesame oil & - & Saline + tests \\
\hline 3 & Progesterone + acute saline & Progesterone & - & Saline + tests \\
\hline 4 & Acute $\mathrm{MgO} \mathrm{NP} 1 \mathrm{mg} / \mathrm{kg}$ & Progesterone & - & $\mathrm{MgO} 1 \mathrm{mg} / \mathrm{kg}+$ tests \\
\hline 5 & Acute MgO NP $2.5 \mathrm{mg} / \mathrm{kg}$ & Progesterone & - & $\mathrm{MgO} 2.5 \mathrm{mg} / \mathrm{kg}+$ tests \\
\hline 6 & Acute $\mathrm{MgO} \mathrm{NP} 5 \mathrm{mg} / \mathrm{kg}$ & Progesterone & - & $\mathrm{MgO} 5 \mathrm{mg} / \mathrm{kg}+$ tests \\
\hline 7 & Acute $\mathrm{MgO}$ NP $10 \mathrm{mg} / \mathrm{kg}$ & Progesterone & - & $\mathrm{MgO} 10 \mathrm{mg} / \mathrm{kg}+$ tests \\
\hline 8 & Progesterone + chronic saline & Progesterone + saline & Saline & Saline + tests \\
\hline 9 & Chronic MgO NP $1 \mathrm{mg} / \mathrm{kg}$ & Progesterone + MgO $1 \mathrm{mg} / \mathrm{kg}$ & $\mathrm{MgO} 1 \mathrm{mg} / \mathrm{kg}$ & $\mathrm{MgO} 1 \mathrm{mg} / \mathrm{kg}+$ tests \\
\hline 10 & Chronic MgO NP 2.5 mg/ kg & Progesterone + MgO 2.5 mg/ kg & $\mathrm{MgO} 2.5 \mathrm{mg} / \mathrm{kg}$ & $\mathrm{MgO} 2.5 \mathrm{mg} / \mathrm{kg}+$ tests \\
\hline 11 & Chronic MgO NP 5 mg/ kg & Progesterone + MgO 5 mg/ kg & $\mathrm{MgO} 5 \mathrm{mg} / \mathrm{kg}$ & $\mathrm{MgO} 5 \mathrm{mg} / \mathrm{kg}+$ tests \\
\hline 12 & Chronic MgO NP 10 mg/ kg & Progesterone + MgO 10 mg/ kg & $\mathrm{MgO} 10 \mathrm{mg} / \mathrm{kg}$ & $\mathrm{MgO} 10 \mathrm{mg} / \mathrm{kg}+$ tests \\
\hline
\end{tabular}


depression. After the tail suspension test, the animal was trained in a memory shuttle box and interval time between two tests was one hour. On the second day of the experiment, the memory test was first taken from each animal and after one hour, the animal was tested for motor activity testing.

\section{Tail suspension test}

Tail suspension test was used for measure the depressive like behavior in the mouse. In this test, mice were suspended on the metal rod stand 50$75 \mathrm{~cm}$ above the table top by the adhesive tape placed approximately $1 \mathrm{~cm}$ from the tip of the tail. Immobility time was recorded during 6 minutes. The animal was considered to be immobile when did not show any movement of the body and hanged passively. A decrease in the immobility period is indicative of antidepressant-like activity (Can et al., 2012).

\section{Step down test}

To evaluate the passive avoidance memory, used a box $(40 \times 30 \times 30 \mathrm{~cm})$ with a wooden platform at the center and head of steel bars that applied electric shocks to the feet of mice by an irritating machine. On training day, the mice were placed in the middle of the box on the platform. As soon as the mice came down from the platform, electric shocks applied for $15 \mathrm{~s}$ to the feet. On the test day without electric shocks, the mice were placed on the platform for $5 \mathrm{~min}$ and time of avoiding down the platform was considered as memory retrieval (Pochwat et al., 2015).

\section{Open field test}

Locomotor activity evaluated by the open field device after 1 hours of memory test. Mice were placed in the middle of the box that had 16 divisions and the numbers of crossing in $5 \mathrm{~min}$ were recorded (Pochwat et al., 2015).

\section{Statistical analysis}

The mean of data was compared between the groups by Graph Pad InStat software (version 3.00) and the statistically significant level was $P<0.05$. Graphical data are expressed as mean \pm SEM. The data analysis was performed by one-way analysis of variance (ANOVA) and Tukey Post hoc statistical tests between multiple groups and student t-test was used for comparison between two groups.

\section{Results}

The effects of acute and chronic administrations of MgO NP on the postpartum depression in the tail suspension test

Figure $1 \mathrm{~A}$ shows the effect of acute administration of different doses of $\mathrm{MgONP}(1,2.5,5$ or $10 \mathrm{mg} / \mathrm{kg})$ on postpartum depression induced by progesterone. Statistical analysis showed that there was no significant difference between saline and sesame oil receiving groups in immobility time $[\mathrm{t}(12)=0.58$, $P<0.5]$ and progesterone caused a significant immobilization than the vehicle group receiving sesame oil $[\mathrm{t}(11)=5.417, \quad P<0.001]$. Acute administration of $\mathrm{MgO} \mathrm{NP}$ (5 or $10 \mathrm{mg} / \mathrm{kg}$ ) reduced immobility time in comparison with the control group $[F(2,14)=28.945, P<0.001]$. Chronic administration of MgO NP $(1,5$ or $10 \mathrm{mg} / \mathrm{kg})$ reduced the immobility time and relative improve the symptoms of depression in female mice (Fig. 1B) $[\mathrm{F}(3,24)=7.731$, $P<0.05, P<0.001]$

\section{Effects of acute and chronic administration MgO} NP on the memory retrieval in the step-down test Figure 2A shows the effect of acute administration of MgO NP $(1,2.5,5$ or $10 \mathrm{mg} / \mathrm{kg})$ in the memory test after postpartum depression induced by progesterone. Statistical analysis showed that PPD significantly decreased memory in comparison with vehicle group $[\mathrm{t}(8)=3.357, \quad P<0.01]$. Acute administration of MgO NP (5 or $10 \mathrm{mg} / \mathrm{kg}$ ) increased step-down latency comparing to the control group $[F(2,13)=21.213, \quad P<0.001] . \quad \mathrm{MgO} \quad \mathrm{NP} \quad(1$ and $2.5 \mathrm{mg} / \mathrm{kg}$ ) increased step-down latency to a lesser extent $\quad[F(2,14)=3.157, \quad P<0.01] . \quad$ Chronic administration of $\mathrm{MgO} \mathrm{NP}$ also increased the time spent on the platform in a dose dependent manner and improved the memory significantly at the doses of 5 and $10 \mathrm{mg} / \mathrm{kg}[F(2,15)=3.510, P<0.05]$ (Fig. 2B).

\section{Effects of acute and chronic administration MgO} NP on the locomotor activity in open field test Effects of MgO NP on locomotor activity in the open field test have shown in Table 2. MgO NP at all doses did not influence the locomotor activity in all groups.

Comparison between the acute and chronic administrations of MgO NP on the postpartum depression and passive avoidance memory in 
A

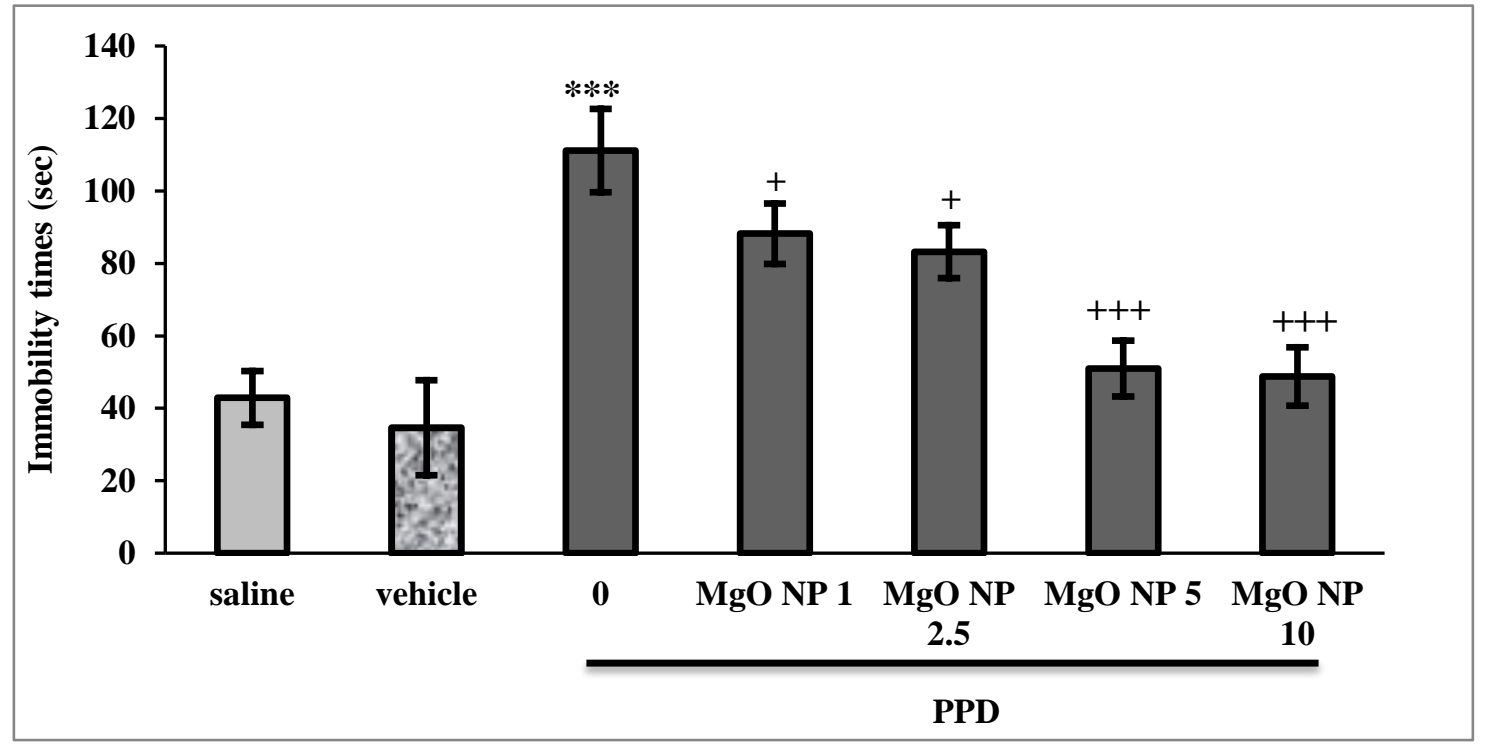

B

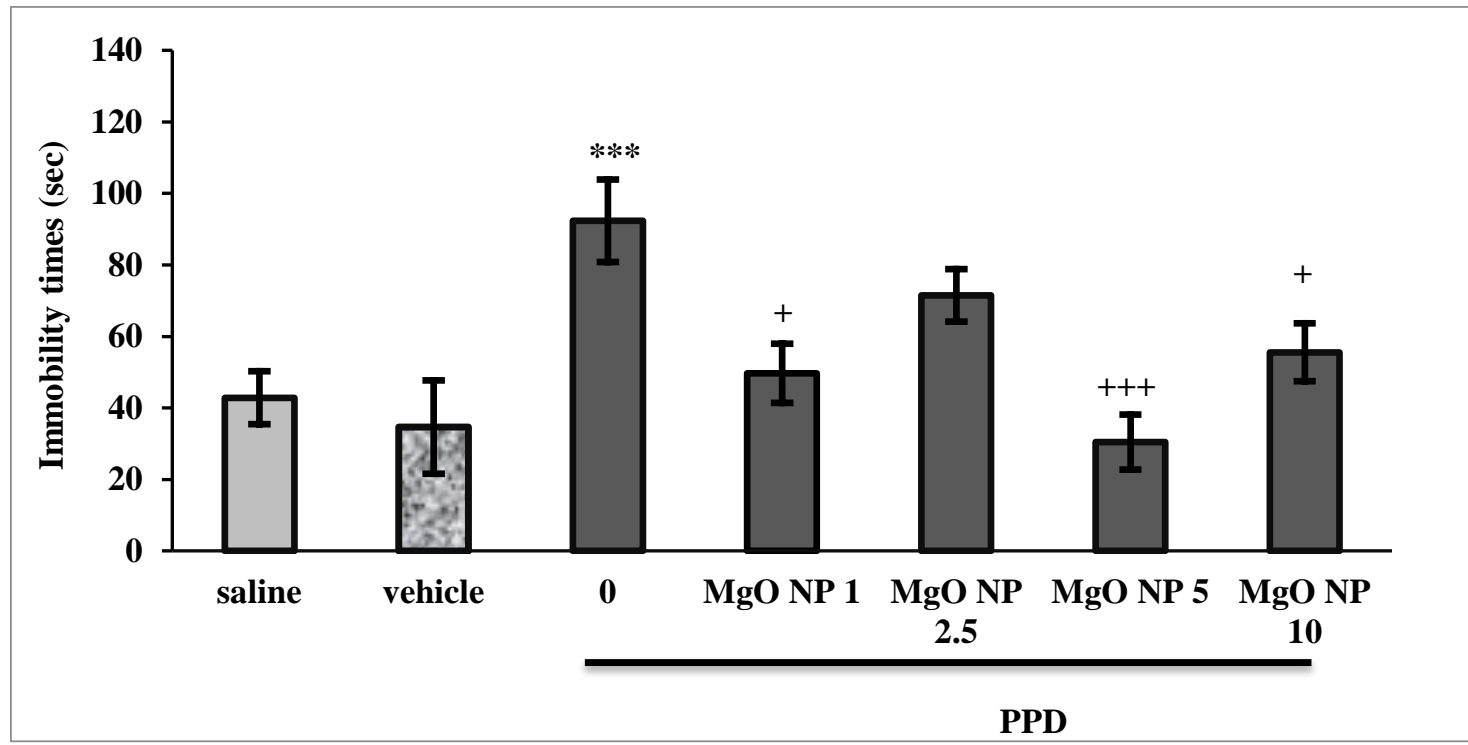

Fig.1. The effects of acute (A) and chronic (B) administration of magnesium oxide nanoparticle (MgO NP) on the postpartum depression (PPT) in the tail suspension test (TST). ${ }^{+} P<0.05$ and ${ }^{+++} P<0.001$ show significant differences vs. control group. ${ }^{* \star} P<0.001$ shows significant differences vs. vehicle group. Each bar shows mean \pm SEM.

\section{PPD model}

Figures 3 and 4 show the effects of acute and chronic administrations of $\mathrm{MgO} \mathrm{NP}$ on depression and memory. Comparing between the acute and chronic administrations of $\mathrm{MgO} \mathrm{NP}$ shows that chronic administration has relatively better effects on depression than acute administration. There is significant difference between acute and chronic administration of $\mathrm{MgO} N P$ in $1 \mathrm{mg} / \mathrm{kg}[\mathrm{t}(10)=3.143$, $\mathrm{P}<0.01$ ] (Fig. 3), while effects of acute administrations of MgO NP on memory were better than chronic and statistical analysis showed that significant differences between acute and chronic administrations of $\mathrm{MgO}$ $\mathrm{NP}$ in 5 and $10 \mathrm{mg} / \mathrm{kg}[\mathrm{F}(3,18)=2.014, P<0.05]$ (Fig. 4).

\section{Discussion}

In this study, we have showed that the withdrawal of chronic treatment of progesterone could induce a sign of depression like behavior in mice. Various factors have been suggested for postpartum depression, including drop of estrogen and progesterone levels (Lashkaripour et al., 2012; Harati et al., 2014). Some studies have shown that a sudden loss of sexual hormones after delivery causes the extreme release of neurotransmitters in the brain that lead to lack of suppression of many depressive factors and indicated that sex hormones suppress stress and tension activities through the 

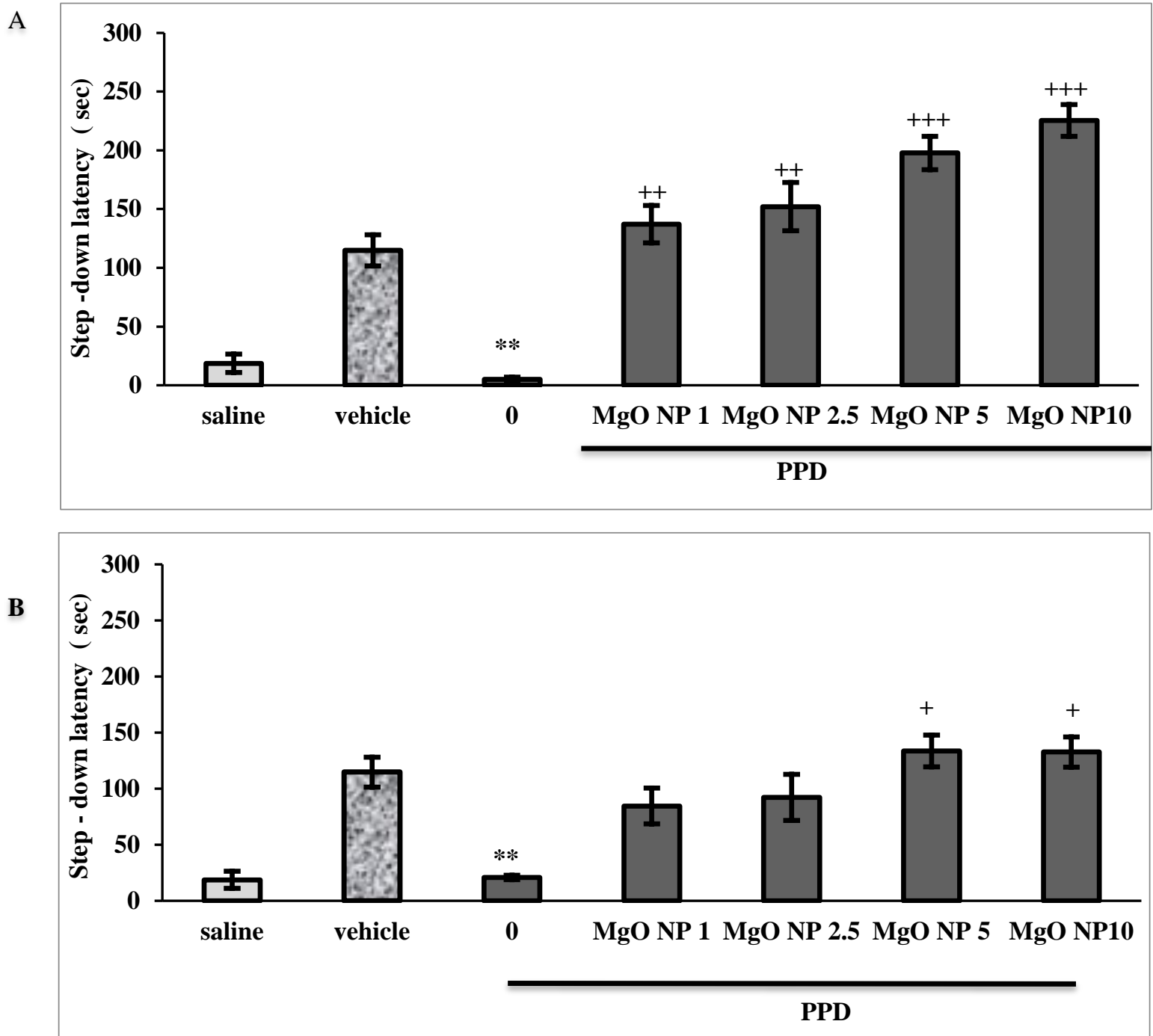

Fig.2. The effects of acute (A) and chronic (B) administration of magnesium oxide nanoparticle (MgO NP) on the memory retrieval in the step-down test. ${ }^{+} P<0.05,{ }^{++} P<0.01$ and ${ }^{+++} P<0.001$ show significant differences vs. control group. ${ }^{\star *} P<0.01$ show significant differences vs. vehicle group. Each bar shows mean \pm SEM.

Table 2: Effects of acute and chronic administration magnesium oxide nanoparticle (MgO NP) on locomotor activity in the open field test.

\begin{tabular}{llll}
\hline Group & Dose $(\mathrm{mg} / \mathrm{kg})$ & Type of injection & Number of crossing \\
\hline Saline & - & - & $142.57 \pm 18.2$ \\
\hline Sesame oil & - & - & $105.16 \pm 13.5$ \\
\hline Pro + saline & - & Acute & $109.16 \pm 11.2$ \\
\hline Pro + saline & - & Chronic & $117.62 \pm 13$ \\
\hline Pro+ MgO NP & 1 & Acute & $105.5 \pm 4.5$ \\
\hline Pro+ MgO NP & 1 & Chronic & $103.5 \pm 10.5$ \\
\hline Pro+ MgO NP & 2.5 & Acute & $124.57 \pm 13.1$ \\
\hline Pro+ MgO NP & 2.5 & Chronic & $161.6 \pm 25.8$ \\
\hline Pro+ MgO NP & 5 & Acute & $91.83 \pm 9.2$ \\
\hline Pro+ MgO NP & 5 & Chronic & $123.6 \pm 28.7$ \\
\hline Pro+ MgO NP & 10 & Acute & $126.14 \pm 11.9$ \\
\hline Pro+ MgO NP & 10 & Chronic & $114 \pm 11.6$ \\
\hline
\end{tabular}




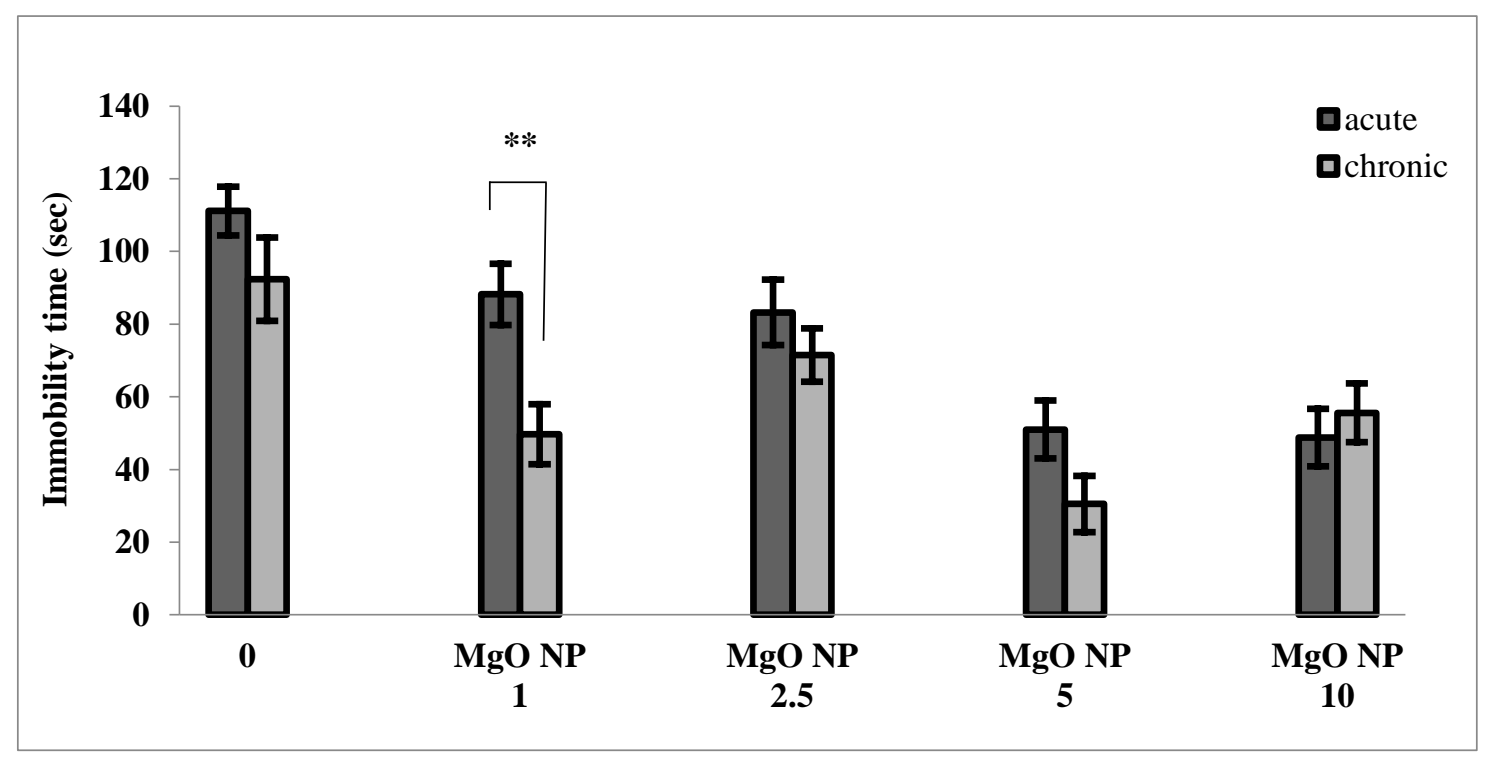

Fig.3. Comparison between an acute and chronic administration of magnesium oxide nanoparticle (MgO NP) on tail suspension test (TST). " $P<0.01$ shows significant differences between acute and chronic administration of MgO NP in $1 \mathrm{mg} / \mathrm{kg}$. Each bar shows mean \pm SEM.

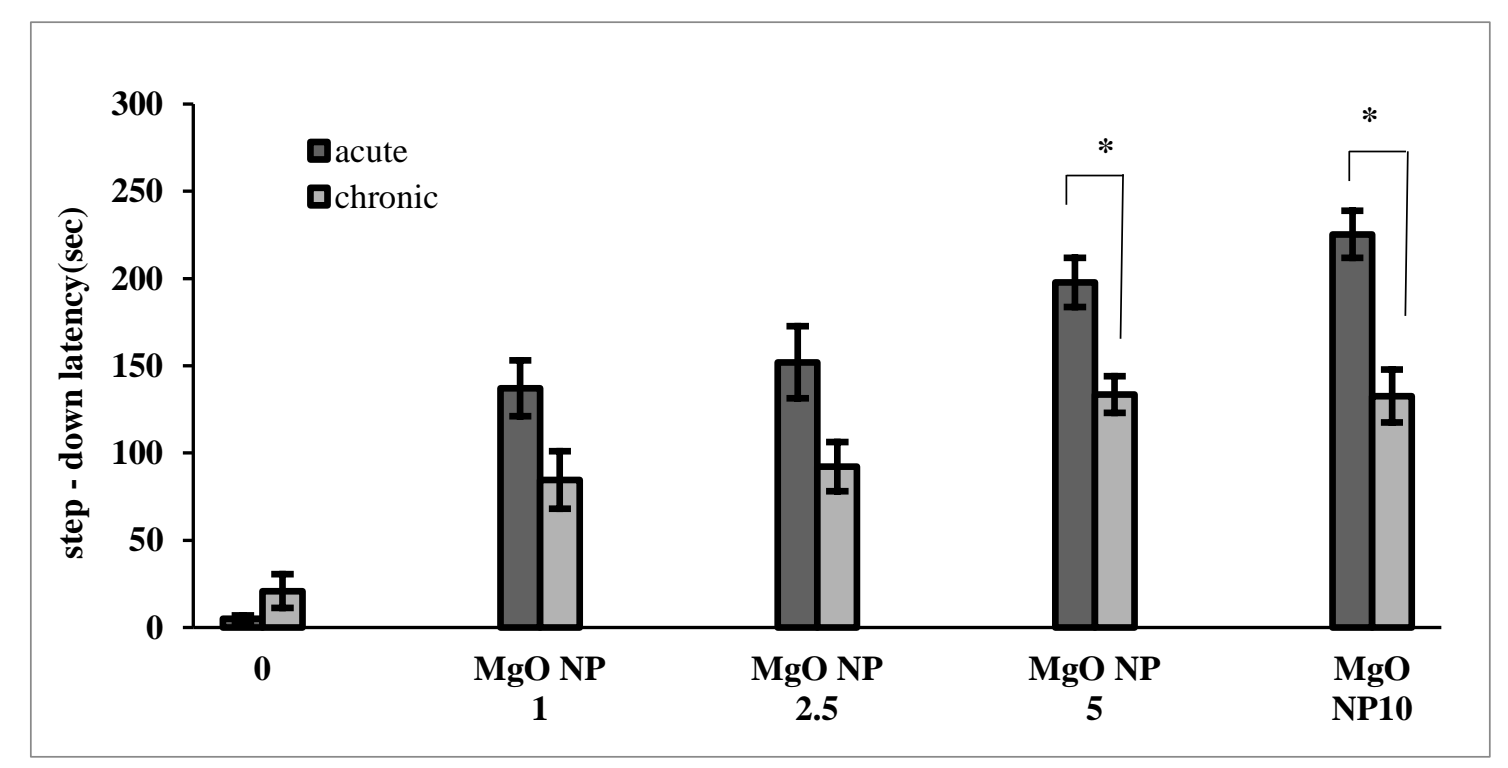

Fig.4. Comparison between acute and chronic administration magnesium oxide nanoparticle ( $\mathrm{MgO} \mathrm{NP}, \mathrm{mg} / \mathrm{kg}$ ) on memory test. ${ }^{*} P<0.05$ shows significant differences between acute and chronic administration of MgO NP in 5 and $10 \mathrm{mg} / \mathrm{kg}$. Each bar shows mean \pm SEM.

hypothalamic-pituitary-adrenal (HPA) axis and reduce depression (Hendrick et al., 1998; Poromaa et al., 2017; Gavin et al., 2018).

The biological mechanisms of sex hormones on the central nervous system have shown that these hormones are involved in the manufacture. of certain neurotransmitters such as dopamine, norepinephrine and serotonin (Amin et al., 2005). These neurotransmitters can be effective on different parts of the brain such as limbic system, hippocampus and vision cortex that are involved in depression (Zhang et al., 2018) and memory (Sarreshtehdar et al., 2012; Failla et al., 2016; Handra et al., 2019) and their reduction are causes of depression through the impact on these areas (Almeida et al., 2012).

Memory impairment induced by postpartum depression in this study is confirmed by Almeida et al. (2012) that showed the short-term memory is defective in postpartum depression. In this study, MgO NPs improved postpartum depression and 
memory impairment in a dose-dependent manner without any changes in locomotor activity. Acute and chronic administrations of MgO NPs have significant effects on duration of immobility time in the tail suspension test and reduced it. However, it seems that chronic administration was able to further reduction than acute administration. Our findings are consistent with previous studies on the effectiveness of magnesium-containing compounds in depressed animal models and human (Poleszak et al., 2004; Eby and Eby, 2010).

Magnesium antidepressant activity is also seen in a short and chronic term usage (Szewczyk et al., 2008). Human studies have shown that the magnesium deficiency is an important factor in developing depression and transmission (Szkup et al., 2017; Phelan et al., 2018) of large amounts of this element from mother-to-child with other nutrients may help occurrence postpartum depression (Eby and Eby, 2010). It has been suggested that magnesium is affected many systems involved in depression (Szkup et al., 2017). Magnesium is an essential cation for women's preconception health and in blood, the concentration of ionized form of magnesium is temporally altered during menstrual cycle, suggesting a correlation between serum sex steroid hormones and circulatingionized magnesium level (Soares and Zitek, 2008). In addition, magnesium level decreases during pregnancy (Grossi et al., 2017).

NMDA receptor is a glutamate-gated channel in the central nervous system that has an important role in learning, memory and in LTP mechanism (Slutsky et al., 2010; Grossi et al., 2017). Synaptic plasticity of LTP is an ability that regulates synaptic transmission performance with the regulation of the NMDA receptor numbers and some changes in its subunits (Hayashi et al., 2014). Increasing of magnesium enhancing block and down-regulating of NMDA receptor and magnesium decline in the brain is allowing the calcium and sodium enter the postsynaptic neuron and potassium ions are removed (Vogel, 2002; Almeida et al., 2012; Hayashi et al., 2014). Increased influx of calcium ions leads to the production of toxic ROS (Bossio et al., 2018)_and nitric oxide radicals and also neuronal death (Dawson and Dawson, 2018). Neural dysfunction and depression due to excessive leakage of calcium in the cells causes a release of glutamate synapses and neurons depolarized and calcium ions in failure further increase the ATP in nerve cells (Eby and Eby, 2010). Some researchers have confirmed that magnesium deficiency with an excess of calcium and glutamate synaptic dysfunction of brain cells can lead to mood and behavior disorders such as depression (Eby and Eby, 2010; Deutschenbaur et al., 2016; Osaghae et al., 2019).

Long-term potentiation modifications are mainly related to the activation of the NMDA receptors. Because transmitter release, neuronal excitability and NMDA activation are modulated by magnesium, a change in brain magnesium homeostasis could affect synaptic strength and plasticity in neuronal networks and consequently could alter memory capacities. According to these postulates, LTP increase in magnesium levels facilitates the conversion of synapses to a plastic state while learning and memory capacities are enhanced in adult animals fed with a diet enriched in magnesium improves learning and memory in aged animals (Vink and Nechifor, 2011). In the present study, it was shown that acute and chronic injections of MgO NPs could significantly affects passive avoidance memory without changes of locomotor activity. It seems that acute injection of $\mathrm{MgO}$ NPs has created better conditions for these nanoparticles effect on memory deficits induced depression model.

In biological systems, MgO NPs can increase ROS expression and toxicity depending on their doses (Hasbullah et al., 2013; Kumaran et al., 2015). Mazaheri et al. (2018) have shown that, high concentrations of MgO NPs induced toxicity in Wistar rats. Also it has been shown that by increasing the nanoparticles concentration ions releasing of them decreased, as well nanoparticles tended to aggregate in the aqueous environments and cellular systems at higher concentrations that these may reduce their efficacy (Auría-Soro et al., 2019; Torabi et al., 2020). It has been shown that MgO NPs can improve longterm memory (24 hours of training) (Abdolahzadeh et al., 2014). On the other hand, there is a direct relationship between magnesium deficiency in the brain and impaired learning ability and increase the concentration of magnesium in addition to increased synaptic plasticity, improves memory by increasing synaptic NMDA receptors (Slutsky et al., 2010; Wang et al., 2013). Also it has been reported that acute injection of MgO NPs could change magnesium level in the serum and hippocampus of animals (Torabi et 
al., 2018). So that probably MgO NPs can cross the blood-brain barrier and play its role in improving memory and depression.

\section{Conclusion}

It seems that, acute administration of MgO NPs can be a suitable supplement for memory impairment induced by postpartum depression and probably aggregation or toxicity of MgO NPs at the highest dose disrupts their activity. Finding the exact mechanisms involved in the antidepressant effects of $\mathrm{MgO}$ NPs and its efficacy in memory improvements need more investigations.

\section{Acknowledgments}

This study was supported by Shahid Chamran University of Ahvaz, Iran, grant number $93 / 302 / 18672$. Hereby, researchers of this study would like to express their sincere gratitude to the esteemed vice-presidency for research of Shahid Chamran University for their financial and moral support.

\section{Conflict of interest}

The authors declare no conflict of interest.

\section{Authors' Contributions}

All authors had an equal role in the design, work, statistical analysis and manuscript writing.

\section{References}

Abdolahzadeh D, Kesmati M, Khaje Por L, Najafzadeh Varzi $\mathrm{H}$. The preventative role of $\mathrm{MgO}$ nanoparticles in amnesia induced by morphine in the mouse. IVJ 2014; 10: $55-64$.

Adabi M, Naghibzadeh M, Adabi M, Zarrinfard MA, Esnaashari SS, Seifalian AM, et al. Biocompatibility and nanostructured materials: applications in nanomedicine. Artif Cells Nanomed Biotechnol 2017; 45: 833-842. https://doi.org/10.1080/21691401.2016.1178134

Almeida L, Jansen K, Köhler C, Pinheiro RT, DaSilva RA, Bonini JS. Working and short-term memories are impaired in postpartum depression. J Affect Disord 2012; 136: 1238-42. https://doi.org/10.1016/j.jad. 2011.09.031

Amin Z, Canli T, Epperson CN. Effect of estrogen-serotonin interactions on mood and cognition. Behav Cogn Neurosci Rev 2005; 4: 43-58. https://doi.org/10.1177/ 1534582305277152

Archakov Al. Nanobiotechnologies in medicine: nanodiagnostics and nanodrugs. Biomed Khim 2010; 56: 7-25. https://doi.org/10.1134/S1990750810010026
Auría-Soro C, Nesma T, Juanes-Velasco P, LandeiraViñuela A, Fidalgo-Gomez $\mathrm{H}$, Acebes-Fernandez $\mathrm{V}$, et al. Interactions of nanoparticles and biosystems: microenvironment of nanoparticles and biomolecules in nanomedicine. Nanomaterials (Basel) 2019; 9. pii: E1365. https://doi.org/10.3390/nano9101365

Bossio C, Abdel Aziz I, Tullii G, Zucchetti E, Debellis D, Zangoli $M$, et al. Photocatalytic activity of polymer nanoparticles modulates intracellular calcium dynamics and reactive oxygen species in HEK-293 cells. Front Bioeng Biotechnol 2018; 6: 114. https://doi.org/10.3389/ fbioe.2018.00114

Can A, Dao DT, Terrillion CE, Piantadosi SC, Bhat S, Gould TD. The tail suspension test. J Vis Exp 2012; 59: e3769. https://doi.org/10.3791/3769

Cuttler C, Graf P, Pawluski JL, Galea LA. Everyday life memory deficits in pregnant women. Can J Exp Psychol 2011; 65: 27-37. https://doi.org/10.1037/a0022844

Dawson TM, Dawson VL. Nitric oxide radicals and also neuronal death. Adv Pharmacol 2018; 82: 57-83. https://doi.org/10.1016/bs.apha.2017.09.003

Deutschenbaur L, Beck J, Kiyhankhadiv A, Mühlhauser M, Borgwardt S, Walter $\mathrm{M}$, et al. Role of calcium, glutamate and NMDA in major depression and therapeutic application. Prog. Neuro-Psychopharmacol Biol Psychiatry 2016; 64: 325-33. https://doi.org/10.1016/ j.pnpbp.2015.02.015

Eby GA, Eby KL. Magnesium for treatment-resistant depression: a review and hypothesis. Med Hypotheses 2010; 74: 649-60. https://doi.org/10.1016/j.mehy.2009. 10.051

Failla MD, Juengst SB, Arenth PM, Wagner AK. Preliminary associations between brain-derived neurotrophic factor, memory impairment, functional cognition, and depressive symptoms following severe TBI. Neurorehabil Neural Repair 2016; 30: 419-30. https://doi.org/10.1177/1545968315600525

Gavin KM, Shea KL, Gibbons E, Wolfe P, Schwartz RS, Wierman ME, et al. Gonadotropin-releasing hormone agonist in premenopausal women does not alter hypothalamic-pituitary-adrenal axis response to corticotropin-releasing hormone. Am J Physiol Endocrinol Metab 2018; 315: 316-325. https://doi.org/ 10.1152/ajpendo.00221.2017

Grossi E, Castiglioni S, Moscheni C, Antonazzo P, Cetin I, Savasi VM. Serum magnesium and calcium levels in infertile women during a cycle of reproductive assistance. Magnes Res 2017; 30: 35-41. https://doi. org/10.1684/mrh.2017.0421

Handra C, Coman O, Coman L, Enache T, Stoleru S, Sorescu AM, et al. The connection between different neurotransmitters involved in cognitive processes. Farmacia 2019; 67: 193-201. https://doi.org/10.31925/ farmacia.2019.2.1

Harati E, Sadeghipour Roodsari H, Seifi B, Kamalinejad M, Nikseresht S. The effect of oral Matricaria Chamomilla extract and selenium on postpartum depression and plasma oxidant-antioxidant system in mice. TUMS $\mathrm{J}$ 2014; 71: 625-634. 
Hasbullah NI, Mazatulikhma MZ, Kamarulzaman N. Nanotoxicity of magnesium oxide on human neuroblastoma SH-SY5Y cell lines. Adv Mater Res 2013; 667: 160-164. https://doi.org/10.4028/ www.scientific.net/AMR.667.160

Hayashi Y, Nabeshima Y, Kobayashi K, Miyakawa T, Tanda K, Takao K, et al. Enhanced stability of hippocampal place representation caused by reduced magnesium block of NMDA receptors in the dentate gyrus. Mol Brain 2014; 7: 44. https://doi.org/10.1186/ 1756-6606-7-44

Hendrick V, Altshuler LL, Suri R. Hormonal changes in the postpartum and implications for postpartum depression. Psychosomatics 1998; 39: 93-101. https://doi.org/ 10.1016/S0033-3182(98)71355-6

Jahangiri L, Kesmati M, Najafzadeh $H$. Evaluation of analgesic and anti-inflammatory effect of nanoparticles of magnesium oxide in mice with and without ketamine. Eur Rev Med. Pharmacol Sci 2013; 17: 2706-10.

Kataja EL, Karlsson L, Huizink AC, Tolvanen M, Parsons C, Nolvi S, Karlsson H. Pregnancy-related anxiety and depressive symptoms are associated with visuospatial working memory errors during pregnancy. J Affect Disord 2017; 218: 66-74. https://doi.org/10.1016/ j.jad.2017.04.033

Kesmati M, Notarki ZS, Issapareh N, Torabi M. Comparison the effect of zinc oxide and magnesium oxide nano particles on long term memory in adult male mice. Zahedan J Res Med Sci 2016; 18: e3473. https://doi.org/10.17795/zjrms-3473

Kesmati M, Torabi M, Teymuri ZH, Malekshahi NH. The interaction between anxiolytic effects of magnesium oxide nanoparticles and exercise in the adult male rat. Nanomed J 2014; 1: 324-330.

Kesmati M, Zadehdarvish F, Jelodar Z, Torabi M. Vitamin C potentiate sedative effect of magnesium oxide nanoparticles on anxiety and nociception in the postpartum depression model. Nanomed J 2017; 4: 17 24.

Kronqvist C. Minerals to dairy cows with focus on calcium and magnesium balance. SLU 2011; P. 40-45.

Kumaran RS, Choi YK, Singh V, Song HJ, Song KG, Kim $\mathrm{KJ}$, Kim HJ. In vitro cytotoxic evaluation of $\mathrm{MgO}$ Nanoparticles and their effect on the expression of ROS genes. Int $\mathrm{J}$ Med Sci 2015; 16: 7551-7564. https://doi.org/10.3390/ijms16047551

Lashkaripour K, Bakhshani NM, Hokmabadi S, Sajjadi A, Safarzadeh Sarasiyabi A. Postpartum depression and related factors: a 4.5 months study. J Fundam Mental Health 2012; 13: 404-412. https://doi.org/10.29252/ hnmj.28.2.115

Li N, Lee B, Liu RJ, Banasr M, Dwyer JM, Iwata M, et al. mTOR-dependent synapse formation underlies the rapid antidepressant effects of NMDA antagonists. Science 2010; 329: 959-64. https://doi.org/10.1126/ science. 1190287

Logan DM, Hilla KR, Jonesa R, Holt-Lunstada J, Larsonab MJ. How do memory and attention change with pregnancy and childbirth? A controlled longitudinal examination of neuropsychological functioning in pregnant and postpartum women. J Clin Exp Neuropsychol 2014; 36: 528-39. https://doi.org/10.1080/ 13803395.2014.912614

Mazaheri N, Naghsh N, Karimi A, Salavati H. In vivo toxicity investigation of magnesium oxide nanoparticles in rat for environmental and biomedical applications. Iran J Biotechnol 2019; 17: e1543. https://doi.org/10.21859/ ijb. 1543

Mohammed L, Gomaa HG, Ragab D, Zhu J. Magnetic nanoparticles for environmental and biomedical applications. Particuology 2017; 30: 1-14. https://doi.org/10.1016/j.partic.2016.06.001

Murck H. Magnesium and affective disorder. Nutr Neurosci. 2002; 5: 375-89. https://doi.org/10.1080/ 1028415021000039194

Nikseresht S, Etebary S, Karimian M, Nabavizadeh F, Zarrindast MR, Sadeghipour HR. Acute administration of $\mathrm{Zn}, \mathrm{Mg}$, and thiamine improves postpartum depression conditions in mice. Arch Iran Med 2012; 15: 306-11.

Osaghae BE, Arrowsmith S, Wray S. Gestational and hormonal effects on magnesium sulfate's ability to inhibit mouse uterine Contractility. Reprod Sci 2019; 17: 1933719119828089. https://doi.org/10.1177/1933719119828089

Phelan D, Molero P, Martínez-González MA, Molendijk M. Magnesium and mood disorders: systematic review and meta-analysis. BJPsych Open 2018; 4: 167-179. https://doi.org/10.1192/bjo.2018.22

Pochwat B, Sowa-Kucma M, Kotarska K, Misztak P, Nowak G, Szewczyk B. Antidepressant-like activity of magnesium in the olfactory bulbectomy model is associated with the AMPA/BDNF pathway. Psychopharmacology (Berl) 2015; 232: 355-67. https://doi.org/10.1007/s00213-014-3671-6

Poleszak E, Szewczyk B, Kêdzierska E, Wlaź P, Pilc A, Nowak G. Antidepressant- and anxiolytic-like activity of magnesium in mice. Pharmacol Biochem Behav 2004; 78: 7-12. https://doi.org/10.1016/j.pbb.2004.01.006

Poleszak, E, Wlaz P, Kedzierska E, Nieoczym D, Wróbel A, Fidecka S,et al. NMDA/glutamate mechanism of antidepressant-like action of magnesium in forced swim test in mice. Pharmacol Biochem Behav 2007; 88: 15864. https://doi.org/10.1016/j.pbb.2007.07.018

Sundström Poromaa I, Comasco E, Georgakis M, Skalkidou A. Sex differences in depression during pregnancy and the postpartum period. J Neurosci Res 2017; 95: 719-730. https://doi.org/10.1002/jnr.23859

Sarreshtehdar M, Gheibi N, Ziaee A, Pahlevan AA. Effect of magnesium administration on passive avoidance memory and formalin-induced nociception in diabetic rats. Trop J Pharm Res 2012; 11: 947-54. https://doi.org/10.4314/tjpr.v11i6.11

Slutsky I, Abumaria N, Wu LJ, Huang C, Zhang L, Li B, et al. Enhancement of learning and memory by elevating brain magnesium. Neuron 2010; 65: 165-77. https://doi.org/10.1016/j.neuron.2009.12.026

Soares CN, Zitek B. Reproductive hormone sensitivity and 
risk for depression across the female life cycle: a continuum of vulnerability. J Psychiatry Neurosci 2008; 33: 331-43.

Spasov AA, lezhitsa IN, Kharitonova MV, Kravchenko MS. Depression-like and anxiety-related behavior of rats fed with magnesium-deficient diet. Zh Vyssh Nerv Deiat Im I P Pavlova 2008; 58: 476-85.

Suresh C, Utkarsh K. Nanoparticles and reproductive toxicity: an overview. Res J Pharm Biol Chem Sci 2013; 4: 1396-1410.

Szewczyk B, Poleszak E, Sowa-Kuæma M, Siwek M, Dudek D, Ryszewska-Pokraoeniewicz B, et al. Antidepressant activity of zinc and magnesium in view of the current hypotheses of antidepressant action. Pharmacol Rep 2008; 60: 588-9.

Szkup M, Jurczak A, Brodowska A, Brodowska A, Noceń I, Chlubek $D$, et al. Analysis of relations between the level of $\mathrm{Mg}, \mathrm{Zn}, \mathrm{Ca}, \mathrm{Cu}$, and $\mathrm{Fe}$ and depressiveness in postmenopausal women. Biol Trace Elem Res 2017; 176: 56-63. https://doi.org/10.1007/s12011-016-0798-9

Tarleton EK, Littenberg B, MacLean CD, Kennedy AG, Daley $C$. Role of magnesium supplementation in the treatment of depression: a randomized clinical trial. PLoS One 2017; 12: e0180067. https://doi.org/10.1371/ journal.pone.0180067

Torabi M, Kesmati M, Galehdari H, Varzi HN, Pourreza N. $\mathrm{MgO}$ and $\mathrm{ZnO}$ nanoparticles anti-nociceptive effect modulated by glutamate level and NMDA receptor expression in the hippocampus of stressed and nonstressed rats. Physiol Behav. 2020; 214: 112727. https://doi.org/10.1016/j.physbeh.2019.112727

Torabi M, Kesmati M, Pourreza N, Najafzadeh Varzi H, Galehdari H. Neurobehavioral and biochemical modulation following administration of $\mathrm{MgO}$ and $\mathrm{ZnO}$ nanoparticles in the presence and absence of acute stress. Life Sci 2018; 203: 72-82. https://doi.org/10.1016/j.Ifs.2018.04.023

Vink R, Nechifor M. Magnesium in the central nervous system. The University of Adelaide South Australia 2011; P. 99-116.

Vogel HG. drug discovery and evaluation-pharmacological assays Germany: Springer Publication 2002; P. 559561.

Walf AA, Frye CA. Estradiol reduces anxiety- and depression-like behavior of aged female mice. Physiol Behav 2010; 99: 169-74. https://doi.org/10.1016/ j.physbeh.2009.09.017

Wang J, Liu Y, Zhou LJ, Wu Y, Li F, Shen KF,et al. Magnesium L-threonate prevents and restores memory deficits associated with neuropathic pain by inhibition of TNF-a. Pain Physician 2013; 16: 563-75.

Wang J, Um P, Dickerman BA, Liu J. Zinc, magnesium, selenium and depression: a review of the evidence potential mechanisms and implications. Nutrients 2018; 10. https://doi.org/10.3390/nu10050584

Wang Q, Xie L, He Z, Di D, Liu J. Biodegradable magnesium nanoparticle - enhanced laser hyperthermia therapy. Int J Nanomedicine 2012; 47: 15-25. https://doi.org/10.2147/IJN.S34902

Wojcik J, Dudek D, Schlegel-Zawadzka M, Grabowska M, Marcinek A, Florek E. Antepartum/postpartum depressive symptoms and serum zinc and magnesium levels. Pharmacol Rep 2006; 58: 571-6. https://doi.org/ 10.2147/TCRM.S109482

Zhang FF, Peng W, Sweeney JA, Jia ZY, Gong QY. Brain structure alterations in depression: psychoradiological Evidence. CNS Neurosci Ther 2018; 24:994-1003. https://doi.org/10.1111/cns.12835 